\title{
Comparative evaluation of root canal preparation using Wave One and Reciproc Systems
}

\author{
Evaluarea comparativă a preparaţiilor canalelor radiculare folosind \\ Sistemele Wave One şi Reciproc
}

\author{
Sînziana Adina Scărlătescu', Paula Perlea ${ }^{1}$, Irina Maria Gheorghiu², \\ Cătălin Nicolae Rolea ${ }^{3}$ \\ ${ }^{1}$ Disciplina de Endodonţie, Facultatea de Medicină Dentară, \\ Universitatea de Medicină şi Farmacie „Carol Davila“, Bucureşti, România \\ 2Disciplina de Odontoterapie Restauratoare, Facultatea de Medicină Dentară, Universitatea de \\ Medicină şi Farmacie „Carol Davila“, Bucureşti, România \\ ${ }^{3}$ Practica privată
}

\begin{abstract}
Aim. The aim of this study was to assess the preparation of root canals using single-file instruments Wave One (Densplay-Sirona) and Reciproc (VDW Gmbh).

Materials and methods. Forty lower mesial and distal root canals were divided into 4 groups $(n=10)$ according to shaping technique; mesial roots were prepared using Reciproc 25 and WaveOne Primay and distal root using Reciproc 40 and Wave One Large respectively. Pre- and post-instrumented radiographs were taken to examine and compare the cross-sectional shape of the canals at 3, 6 and $9 \mathrm{~mm}$.

Results. Wave One led to bigger diameters especially at $9 \mathrm{~mm}$, the difference being of $0,22 \mathrm{~mm}$ versus Reciproc 25 and $0,14 \mathrm{~mm}$ versus Reciproc 40.

Conclusions. The Wave One system produced a bigger tapered root canal preparation versus the Reciproc system.
\end{abstract}

Keywords: Ni-Ti instruments, cross-sectional diameters, Reciproc, Wave One

\section{REZUMAT}

Scop. Studiul şi-a propus evaluarea comparativă a preparării canalelor radiculare folosind sistemele rotative Reciproc (VDW Gmbh) şi Wave One (Densplay-Sirona).

Materiale şi metode. Patruzeci de rădăcini meziale şi distale ale molarilor inferiori au fost împărţite în 4 grupe $(n=10)$ în funcţie de tehnica de preparare; rădăcinile meziale au fost preparate cu sistemele Reciproc 25 şi WaveOne Primary, rădăcinile distale cu Reciproc 40 şi WaveOne Large. Au fost realizate radiografii înainte şi după preparare pentru a examina şi a compara diametrele pe secţiune ale canalelor la 3,6 şi $9 \mathrm{~mm}$.

Rezultate. WaveOne a înregistrat cele mai mari diametre în special la $9 \mathrm{~mm}$, diferenţa fiind de 0,22 $\mathrm{mm}$ faţă de Reciproc 25 şi 0,14 mm faţă de Reciproc 40.

Concluzii. Sistemul WaveOne a produs o preparaţie mai mare a canalelor radiculare faţă de sistemul Reciproc.

Cuvinte cheie: instrumente $\mathrm{Ni}-\mathrm{Ti}$, diametre pe secţiune, Reciproc, Wave One

\section{INTRODUCERE}

Sistemele rotative cu mişcare reciprocă sunt o alternativă nouă la varianta clasică de sisteme rotative cu mişcare de rotaţie continuă. Acele ce folo- sesc mişcare reciprocă au o formă specială, mişcarea imprimată acului de micromotor este caracteristică: o mişcare în sens orar, urmată de o mişcare în sens antiorar. Sistemele reciproce încearcă să rezolve o serie de probleme sesizate de-a lungul tim- 
pului la varianta clasică de sisteme rotative cu rotaţie continuă: folosirea unui singur ac pentru prepararea unui canal, ceea ce reduce durata tratamentului; acul este folosit o singură dată astfel încât nu mai necesită sterilizare şi se elimină riscul de contaminare încrucişată; mişcarea de reciprocitate reduce considerabil riscul de fractură a instrumentului (acul este deşurubat din dentină în timpul mişcării în sens anti-orar), păstrează mai bine anatomia canalului (prin mişcarea reciprocă acul se autocentrează în canal), iar în cazul canalelor cu diametre mai mari nu mai este necesară realizarea traseului de alunecare $(1,2)$.

Sistemul RECIPROC (VDW Gmbh, Munchen, Germany) a apărut în anul 2011 şi este format dintrun număr mic de ace, 3 , ce folosesc o mişcare de reciprocitate. Un singur ac reciproc este necesar pentru prepararea în totalitate a unui canal radicular, uneori fiind necesară şi realizarea traseului de alunecare. Acul R 25/.08 (roşu) este recomandat pentru majoritatea situaţiilor clinice, la canalele cu diametre reduse. Următoarele ace, R 40/.06 (negru) şi R 50/05 (galben) sunt recomandate pentru canalele cu diametre medii sau mari. Instrumentele Reciproc sunt realizate de aliaj de Ni-Ti, M-Wire, au o formă în secţiune transversală de S, reducând contactul dintre ac şi dentina intracanaliculară, scăzând riscul de fracturare.

Sistemul Wave One (Densplay-Sirona, Ballaigues, Switzerland) este compus tot din 3 ace de diametre diferite. Este proiectat a se folosi un singur ac WO pentru prepararea unui canal. Acul Wave One Small 21/.06 (galben) este indicat în canalele înguste, acul Wave One Primay 25/.08 (roşu) este indicat pentru majoritatea cazurilor clinice, iar acul Wave One Large 40/.08 (negru) este indicat pentru canalele cu diametru mare. Instrumentele Wave One sunt realizate din aliaj de Ni-Ti M-Wire, cu o duritate şi rezistenţă la oboseală ciclică de 4 ori mai mare ca în cazul aliajului clasic de Ni-Ti (3).

Scopul studiului a fost evaluarea comparativă a preparării şi lărgirii canalelor radiculare ale molarilor inferiori folosind sistemele rotative Reciproc şi Wave One.

Obiectivele studiului au fost:

1. măsurarea diametrelor iniţiale ale canalelor radiculare la 3, 6 şi $9 \mathrm{~mm}$, corespunzător treimilor apicală, medie şi coronară
2. măsurarea diametrelor canalelor la 3, 6 şi 9 mm după prepararea lor folosind cele 2 sisteme rotative

3. evaluarea accidentelor ce pot apare în cursul lărgirii folosind aceste sisteme

\section{MATERIALE ŞI METODE}

Acest studiu a fost realizat pe un număr de 40 de canale ale rădăcinilor meziale şi distale ale molarilor inferiori. După realizarea cavităţii de acces şi verificarea corectitudinii acestora, au fost identificate orificiile de emergenţă a canalelor radiculare, cu ajutorul unui ac Kerr File \#10 (VDW V20070602510). Ulterior, dinţii au fost secţionaţi vertical, la jumătatea suprafeţei ocuzale, interradicular, cu ajutorul unei freze efilate diamantate de turbină (Medin 146519020) de granulaţie galbenă, rezultând separarea rădăcinilor mezială şi distală.

Canalele au fost împărţite în 4 grupe astfel:

- grupul 1: 10 canale meziale tratate cu Reciproc R25

- grupul 2: 10 canale meziale tratate cu WO Primary

- grupul 3: 10 canale distale tratate cu Reciproc R40

- grupul 4: 10 canale distale tratate cu WO Large

Lungimea de lucru a fost măsurată între vârful de cuspid şi apex, reperul apical fiind acul Kerr 10 vizibil în apex. Pentru măsurare s-a folosit o riglă endodontică (Minifix, VDW - V040179). După permeabilizare, s-a realizat traseul de alunecare pentru toate canalele, cu ac Kerr file \#15. Pentru realizarea etapelor de tratament rotativ, s-a folosit un micromotor VDW Silver care permite mişcare reciprocă, care dispune de mai multe programe, având şi funcţie auto-reverse. Am folosit pentru acest studiu programul RECIPROC ALL pentru acele R 25, R 40 şi programul WAVEONE ALL pentru acele WO Small şi WO Primary. Fiecare etapă a tratamentului mecanic de canal a fost realizată sub irigare cu hipoclorit de sodiu 2,3\% şi EDTA $17 \%$ soluţie. Pentru irigare s-a folosit o seringă cu vârful înfiletabil, cu capacitatea de $5 \mathrm{ml}$ şi un ac de lavaj cu deschidere laterală G30 (Elsodent ED30100). Pentru fiecare canal s-a folosit un volum de aproximativ $10 \mathrm{ml}$ de hipoclorit de sodiu 2,3\% şi 2 $\mathrm{ml}$ de EDTA soluţie.

Dinţii au fost radiografiaţi atât înainte, cât şi după preparare, astfel încât să nu apară suprapuneri 
de planuri, vizibilitatea canalelor fiind foarte bună. Pe radiografiile astfel realizate s-au determinat diametrele canalului după prepararea cu sistemele reciproce, la 3, 6 şi 9 mm (Fig. 1)

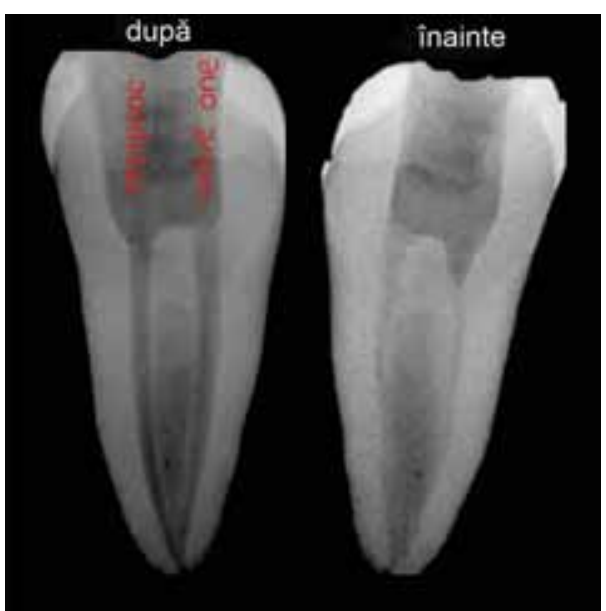

FIGURA 1. Radiografiile inițială şi după prepararea canalelor meziale cu R 25 şi WO Primary

Pentru determinarea diametrelor canalelor la lungimile stabilite anterior s-au folosit marcajele de pe marginea filmului radiologic, marcaje date de către centrul de radiologie ca fiind $1: 1$. Cu ajutorul riglei s-au trasat marcajele de la marginea filmului radiologic și s-a măsurat diametrul canalului inţial la $3 \mathrm{~mm}$ de apex, la $6 \mathrm{~mm}$ de apex şi la $9 \mathrm{~mm}$ de apex. Folosind inscripţiile de pe marginea filmului radiologic, cu ajutorul programul Paint 3D, s-au trasat cu linii de culoare roşie măsurătorile deja existente pe film la $0 \mathrm{~mm}, 0,5 \mathrm{~mm}, 1 \mathrm{~mm}, 1,5 \mathrm{~mm}$, $2 \mathrm{~mm}, 2,5 \mathrm{~mm}, 3 \mathrm{~mm}, 3,5 \mathrm{~mm}, 4 \mathrm{~mm}$. Între 2 linii roşii au fost trasate atât linii orizontale galbene, cât şi linii verticale verzi, la 0,1 mm una de alta (Fig. 2)

\section{REZULTATE}

După măsurarea diametrelor canalelor lărgite cu R25, a rezultat o preparare intensă a canalului radicular în primii 3 milimetri apical, preparare ce ulterior creşte, dar într-o manieră mai moderată. Comparativ cu R25, WO Primary a condus spre diametre medii mai mari la toate cele trei niveluri studiate (Tabelul 1). Acest ac prepară intens porţiunea apicală a canalului, iar preparaţia continuă cu aproximativ aceeaşi conicitate şi pe restul suprafeţei canalului radicular. O exemplificare comparativă se poate observa la canalele meziale ale unei rădăcini inferioare preparată diferit cu cele 2 sisteme (Fig. 3).

TABELUL 1. Diametrele medii inițiale şi în urma preparațiilor cu R25 şi WO Primay la cele 3 niveluri studiate

\begin{tabular}{|l|c|c|c|}
\hline & $\begin{array}{c}\text { Diametre medii } \\
\text { inițiale }\end{array}$ & $\begin{array}{c}\text { Diametre medii } \\
\text { R25 }\end{array}$ & $\begin{array}{c}\text { Diametre medii } \\
\text { WO Primary }\end{array}$ \\
\hline La $3 \mathrm{~mm}$ & $0,28 \mathrm{~mm}$ & $0,52 \mathrm{~mm}$ & $0,54 \mathrm{~mm}$ \\
\hline La $6 \mathrm{~mm}$ & $0,46 \mathrm{~mm}$ & $0,71 \mathrm{~mm}$ & $0,85 \mathrm{~mm}$ \\
\hline La $9 \mathrm{~mm}$ & $0,55 \mathrm{~mm}$ & $0,85 \mathrm{~mm}$ & $1,07 \mathrm{~mm}$ \\
\hline
\end{tabular}

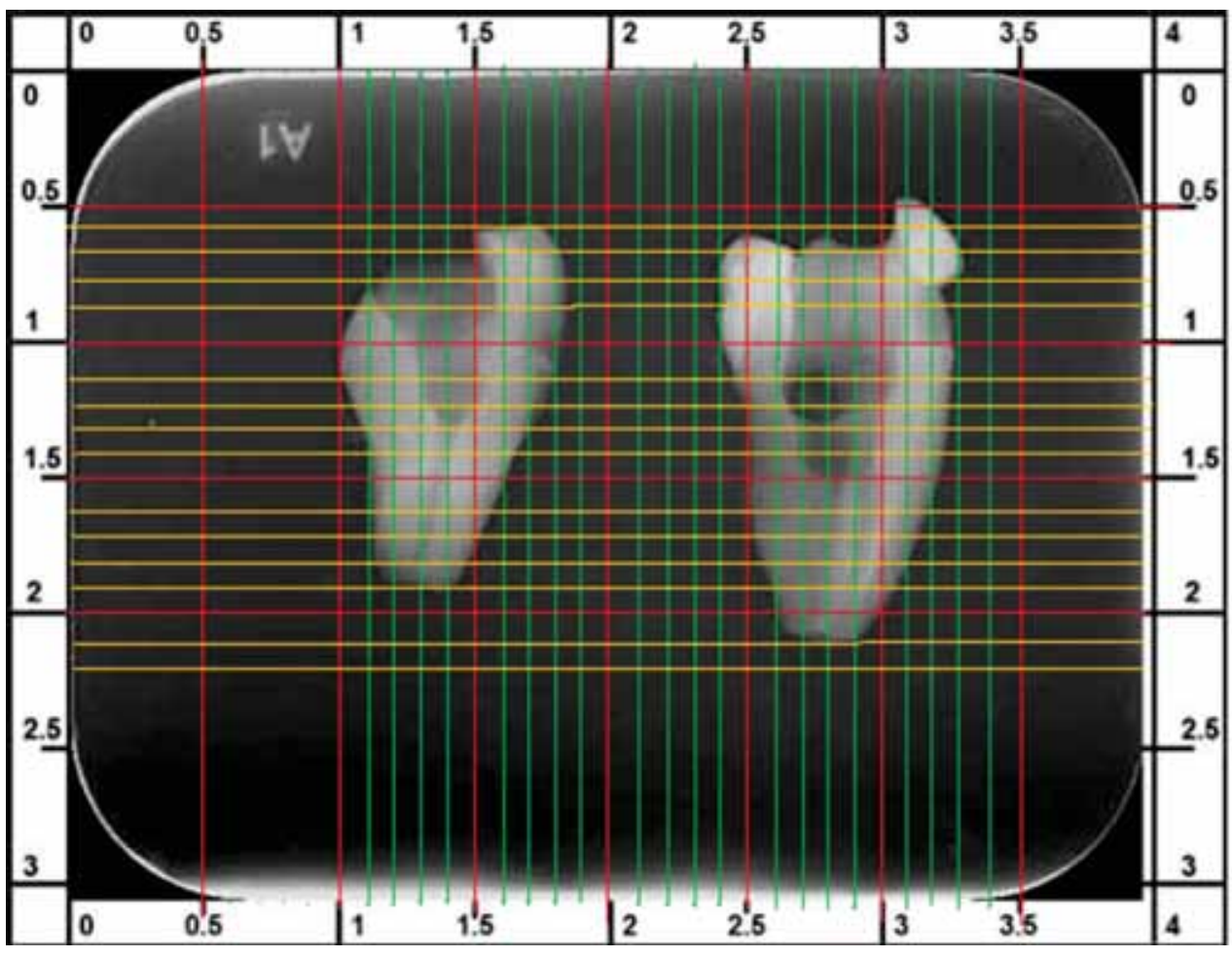

FIGURA 2. Metoda de măsurare a diametrelor inițiale şi după preparare 


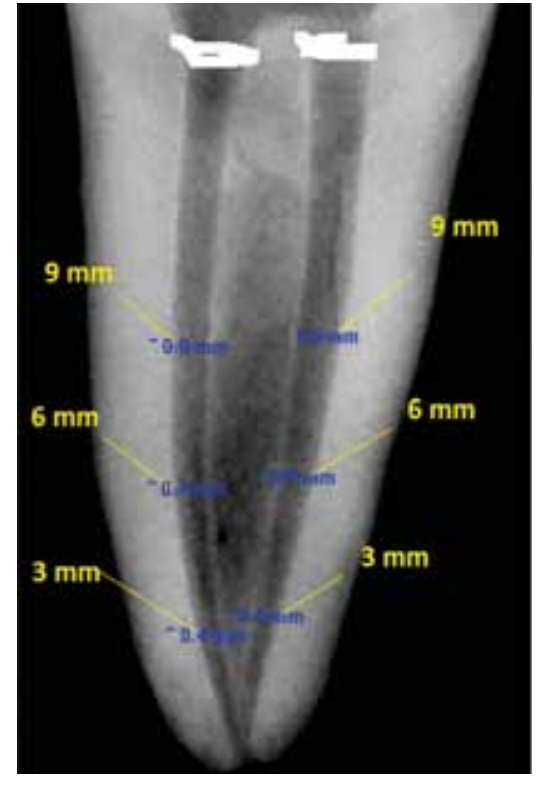

FIGURA 3. Diametre rezultate după preparare cu R25 (stânga) şi WO Primary (dreapta) la cele 3 niveluri, la canalele meziale ale molarului 1 inferior

Sistemul WO Primary a produs o preparaţie mai mare a canalelor radiculare, diferenţele între cele 2 sisteme fiind de $0,02 \mathrm{~mm}$ la $3 \mathrm{~mm}$ de apex, 0,14 $\mathrm{mm}$ la $6 \mathrm{~mm}$ şi $0,22 \mathrm{~mm}$ la $9 \mathrm{~mm}$, cea mai mare diferenţă între diametrele măsurate dintre cele două ace (Fig. 4).

În cazul canalelor distale, s-a constatat că acul R 40 prepară intens canalul pe porţiunea apicală şi mai puţin în porţiunea coronară, în timp ce acul WO Large prepară canalul intens în treimea apicală şi continuă în acelaşi registru pe toată lungimea canalului radicular (Tabelul 2).

TABELUL 2. Diametrele canalelor distale preparate cu $R$ 40 şi WO Large la cele 3 niveluri studiate

\begin{tabular}{|l|c|c|}
\hline & Diametre medii R 40 & Diametre medii WO Large \\
\hline La $3 \mathrm{~mm}$ & $0,66 \mathrm{~mm}$ & $0,77 \mathrm{~mm}$ \\
\hline La $6 \mathrm{~mm}$ & $0,98 \mathrm{~mm}$ & $1,04 \mathrm{~mm}$ \\
\hline La $9 \mathrm{~mm}$ & $1,15 \mathrm{~mm}$ & $1,26 \mathrm{~mm}$ \\
\hline
\end{tabular}

La toate cele 3 niveluri, acul WO Large a condus spre o preparaţie mai mare a canalelor, cu îndepărtarea unei cantităţi mai mari de dentină comparativ cu acul $\mathrm{R} 40$, rezultând o diferenţă între cele 2 sisteme de $0,11 \mathrm{~mm}$ la $3 \mathrm{~mm}$ de apex, $0,06 \mathrm{~mm}$ la 6 $\mathrm{mm}$ şi $0,14 \mathrm{~mm}$ la $9 \mathrm{~mm}$ (Fig. 5).

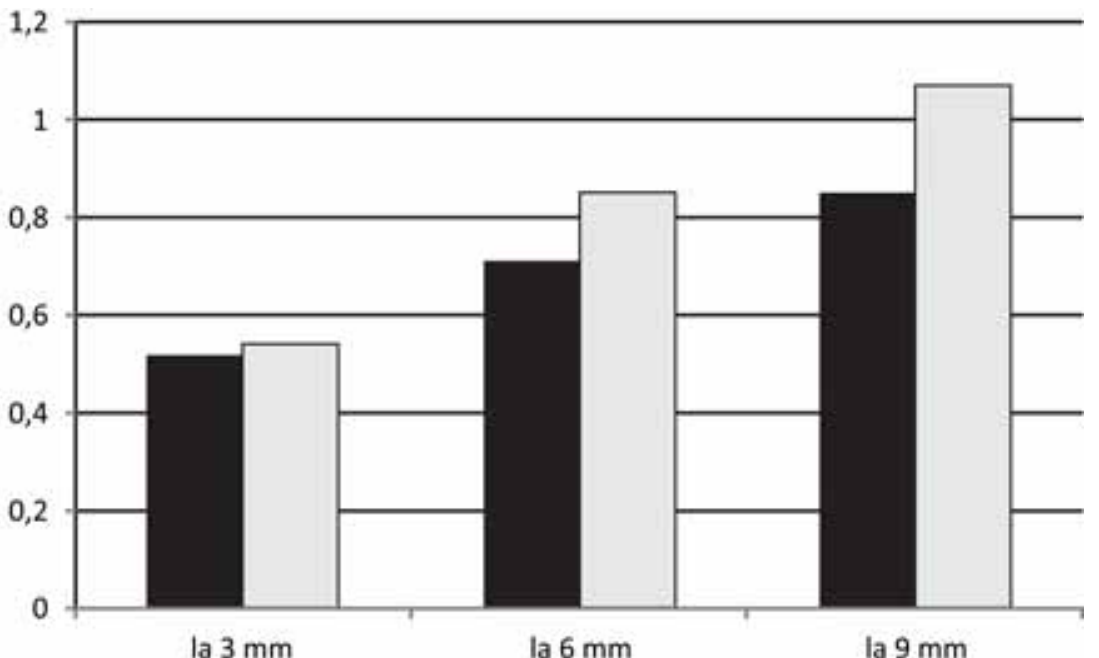

- Reciproc $\square$ Wave One

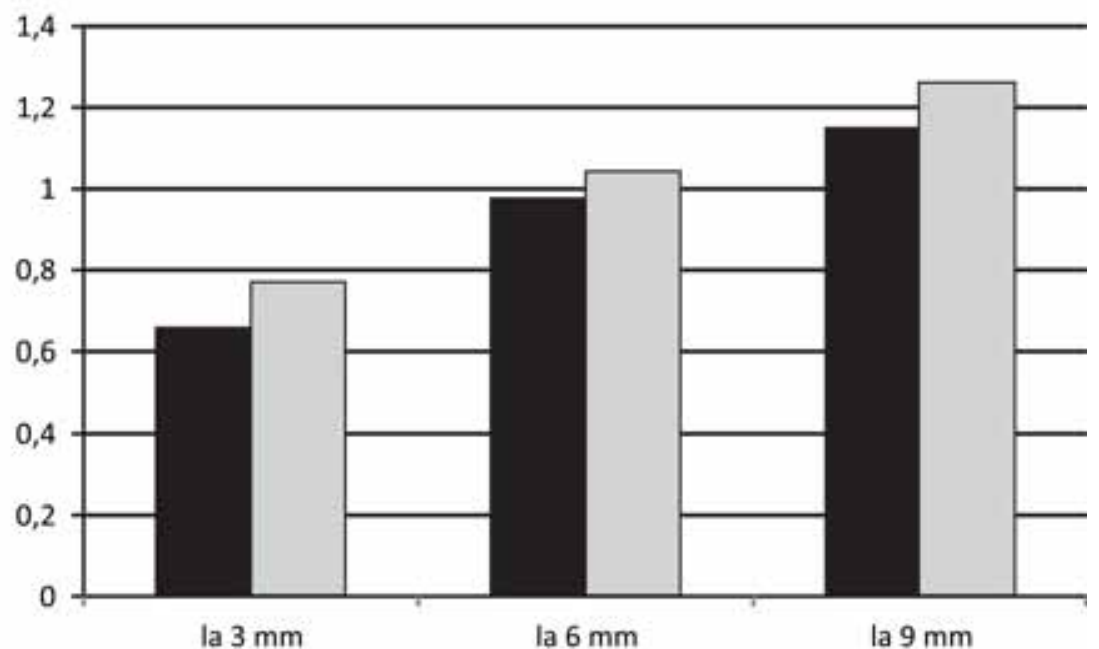

Reciproc $\square$ Wave one
FIGURA 4. Reprezentare grafică comparativă a diametrelor medii ale canalelor preparate cu R25 şi WO Primary, la cele 3 niveluri studiate
FIGURA 5. Reprezentare grafică comparativă între preparațiile canalelor radiculare obținute cu $R 40$ şi WO Large la cele 3 niveluri studiate 
În cursul preparării canalelor radiculare, am constatat ca principal accident fracturarea instrumentelor endodontice rotative. Acestea au fost $1 \mathrm{ac}$ R 25 şi 2 ace WO Primary fracturate în porţiunea apicală a canalelor meziale.

\section{DISCUŢII}

Sistemele care folosesc mişcarea reciprocă pentru a lărgi canalele radiculare au ca principal scop prepararea mai rapidă şi mai sigură a acestora. Mişcarea reciprocă a fost propusă tocmai pentru a realiza o preparaţie cât mai corectă a canalului radicular, uniform progresivă şi eficientă pentru curăţarea, dezinfecţia şi obturarea în bune condiţii a acestuia $(4,5)$. Cele două sisteme studiate sunt confecţionate din acelaşi aliaj (M-wire), dar au aspecte diferite pe secţiune, formă de $\mathrm{S}$ în cazul sistemului Reciproc şi aspect triunghiular concav în cazul Wave One (6). Pentru a ne apropia cât mai mult de realitatea clinică, în acest studiu am folosit molari inferiori extraşi recent din motive parodontale şi ale căror canale meziale subţiri şi parţial calcificate au constituit uneori o adevărată provocare pentru cele 2 sisteme.

Cele două ace au un design extern asemănător în treimea apicală, ambele ace prezintă un diametru la vârf de 25 ISO şi o conicitate de $8 \%$ în primii 3 milimetri apicali, drept pentru care şi preparaţiile realizate de acestea seamănă ca diametre în treimea apicală. Astfel, diferenţa dintre diametrele medii la $3 \mathrm{~mm}$ de apex este minoră, de doar $0,02 \mathrm{~mm}$.

După cei trei milimetri apicali, forma acului se schimbă, acul reciproc are o conicitate mai mică, cu diametrul destul de mic în porţiunile coronare, în timp ce acul WO are diametrele mai mari, prepară o cantitatea mai mare de dentină din porţiunea coronară a canalului radicular, impunând canalului o conicitate mai mare în zona coronară. Astfel, se constată diferenţa de $0,14 \mathrm{~mm}$ la $6 \mathrm{~mm}$ de apex între diametrele medii ale preparaţiilor.

Acelaşi lucru este valabil în continuare pe porţiunea coronară a canalului, diferenţa diametrelor medii la $9 \mathrm{~mm}$ fiind de $0,22 \mathrm{~mm}$ între cele două ace. Cele două sisteme cu mişcare reciprocă prezintă aceeaşi formă în primii $3 \mathrm{~mm}$ apicali, ca diametru şi conicitate, diferenţa dintre cele două fiind dată de abordarea după cei $3 \mathrm{~mm}$ apicali ai acului. Acul Wave One Primary creşte către coronar cu o conicitate mare, îndepărtează o cantitate mare de dentină din zona coronară mai ales, intrarea în canalul radi- cular fiind de mari dimensiuni. Acul Reciproc R25 are o conicitate mare în primii $3 \mathrm{~mm}$ apicali, însă conicitatea începe să descrească către coronar, îndepărtând cantităţi mai mici de dentină în porţiunea coronară (7).

Acele R 40 şi WO Large au diametrul la vârf identice, de 40 ISO, dar conicitatea în primii 3 milimetri apicali este diferită, la acul R40 este de $6 \%$, în timp ce la acul WO Large este de $8 \%$. Apare o primă diferenţă între cele două ace, în timp ce diametrul apical este egal la cele două, conicitarea diferă cu 2\% în favoarea acului Wave One Large. Din această primă diferenţă va rezulta şi diferenţa de preparare. La $3 \mathrm{~mm}$ diferenţa între diametrele medii a fost de 0,11 mm în favoarea WO Large şi aceeaşi situaţie am constatat-o şi la $9 \mathrm{~mm}$, unde acul WO Large a îndepărtat o cantitate mai mare din dentina de la nivel cervical. În schimb, la $6 \mathrm{~mm}$ de apex, acele impun o formă asemănătoare canalului radicular, cu o diferenţă medie de doar $0,06 \mathrm{~mm}$ între cele două, în favoarea acului din sistemul Wave One.

Fractura acelor a apărut numai în cazul lărgirii canalelor meziale subţiri şi curbe şi a apărut mai des la sistemul Wave One, cu un ac în plus faţă de $R$ 25. Într-un studiu realizat de Alberto Dagna şi colaboratorii din 2014 (8), aceştia au evaluat gradul de rezistenţă la oboseală ciclică a 3 sisteme endodontice - Reciproc (VDW), Wave One (DensplaySirona) şi One Shape (Micro Mega) - şi au ajuns la concluzia că acul Reciproc este cel mai rezistent, urmat de Wave One şi One Shape. La aceeaşi concluzie au ajuns şi Hyneo-Cheol Kim şi colaboratorii, în anul 2012 (9), într-un studiu ce a avut ca scop compararea oboselii ciclice şi a rezistenţei la torsiune a sistemelor Reciproc şi Wave One. În urma studiului, aceştia au arătat că Reciproc prezintă o oboseală ciclică mai mare, dar rezistenţă la torsiune mai mică, în timp ce Wave One a avut o rezistenţă la torsiune mai mare. Ei recomandă utilizarea sistemului Reciproc pentru prepararea canalelor cu o curbură mai accentuată, datorită rezistenţei sale bune la oboseală, şi sistemul Wave One pentru canale înguste care ar putea induce tensiuni de torsiune mai mari (9).

\section{CONCLUZII}

Prezentul studiu a arătat capacitatea ambelor sisteme de a produce preparaţii corecte, uniform 
progresive, conform cu anatomia iniţială a canalelor radiculare. Sistemul Wave One a condus spre preparaţii de diametre superioare sistemului Reciproc, cea mai mare diferenţă fiind înregistrată la preparaţia treimii coronare folosind WaveOne Primary.

\section{BIBLIOGRAFIE}

1. Yared G. Canal preparation using only one Ni-Ti rotary instrument: preliminary observations. Int Endod J. 2008; 41: 339-334.

2. Webber J., Machtou P., Pertot W., Kuttler S., Ruddle C., West J. The WaveOne single-file reciprocating system. Roots 2011: 28-33.

3. Filpo-Perez C., Bramante C.M., Villas-Boas M.H., Duarte M.A.H., Versiani M.A., Ordinolo-Zapata R. Micro-computed tomographic analysis of the root canal morphology of the distal root of mandibular first molar. J Endod 2015; 41(2):231-236.

4. Plotino G., Grande N.M., Testarelli L., Gambarini G. Cyclic fatigue of Reciproc and WaveOne reciprocating instruments. Int Endod J 2012; 45:614-618.

5. Topçuoğlu H.S., Düzgün S., Akti A., Topçuoğlu G. Laboratory comparison of cyclic fatigue resistance of WaveOne Gold, Reciproc and WaveOne files in canals with a double curvature. Int Endod J 2017; 50:713- 717.

\section{Mențiune}

Toţi autorii au contribuţie egală în realizarea articolului.

Conflict of interest: none declared Financial support: none declared

6. Machado M.E., Nabeshima C.K., Leonardo M.F.P., Reis F.A.S., Britto M.L.B., Cai S. Influence of reciprocating single-files and rotary instrumentation on bacterial reduction on infected root canals. Int Endod J 2013; 46:1083-1087.

7. Bürklein S., Hinschitza K., Dammaschke T, Schäffer E. Shaping ability and cleaning effectiveness of two-single files systems in severly curved root canals of extracted teeth: Reciproc and WaveOne versus Mtwo and ProTaper. Int Endod J 2012; 45:449-461.

8. Dagna A., Poggio C., Beltrami R., Colombo M., Chiesa M., Bianchi S. Cyclic fatigue resistance of OneShape, Reciproc san WaveOne. J of Conservativ Dent, 2014: 250-254.

9. Hyeon-Cheol K., Gray S.-P., WooCheol L. Cyclic fatigue and torsion resistance of two new nikel-titan instruments used in reciprocation motion: Reciproc versus WaveOne, $\mathrm{J}$ of Endod, 2012: 541-544. 